\section{Imaging in a 35-year-old woman with progressive headache}

Choosing Wisely Canada

\section{Santanu Chakraborty MD, William D. Miller MD}

\begin{abstract}
A 35-year-old woman presents with a onemonth history of progressive global headaches, which last from hours to a day. The headaches are associated with visual blurring and paresthesia involving the left side of her face. She sometimes experiences nausea and vomiting with the headaches. On a few occasions, her headaches have been associated with sexual intercourse. Her headaches are now affecting her ability to work. She has a history of occasional headaches. A distant relative on the maternal side of her family died from subarachnoid hemorrhage associated with a cerebral aneurysm. On examination, the patient is slightly overweight and there is possibly some blurring of the optic disc margins bilaterally. Neurological examination is otherwise unremarkable.
\end{abstract}

\section{What diagnoses should be considered?}

The differential diagnosis includes primary headache (e.g., migraine, tension headache) and idiopathic intracranial hypertension. Secondary headache associated with aneurysm or intracranial masses should also be considered.

\section{Based on the patient's symptoms and examination, should she be sent for imaging of her head?}

This patient may benefit from imaging because she has progressive headaches and findings that suggest the possibility of underlying pathology.

The frequency of headache complaints and the low yield of positive results create a substantial challenge in use of imaging. A study by You and colleagues ${ }^{1}$ assessed indications for and results of nearly 12000 requests for outpatient computed tomography (CT) in 20 Ontario hospitals. In this study, the head was the most requested body part for CT (35\%), with $26 \%$ of these scans requested for headache. Less than $2 \%$ of these were positive for an abnormality that could explain the headache. A systematic re- view performed for a guideline on headache by the American College of Radiology ${ }^{2}$ found that there is a very low yield of positive results for imaging in patients presenting with isolated headache; the incidence of abnormalities was as low as $0.4 \%$, and not all of these were clinically significant. There are potential risks with neuroimaging, including false-positive results that may worry the patient and lead to additional procedures. $^{3}$

Headaches associated with "red flags" merit imaging (Box 1). ${ }^{4}$ These include those associated with thunderclap onset (i.e., instantly peaking pain), new onset in pregnancy, suspected meningitis, immunosuppression, ongoing or suspected recurrence of malignancy, or ipsilateral Horner syndrome with suspected arterial dissection..$^{4-6}$

As per the recommendations of the Choosing Wisely and Choosing Wisely Canada campaigns, ${ }^{4,6}$ neuroimaging studies are not required in patients with stable headaches that meet the criteria for migraine. A similar recommendation holds for typical cluster headaches. ${ }^{3}$ The likelihood of positive findings on imaging is not increased when headaches are accompanied by symptoms such as numbness and visual blurring without any abnormal neurologic findings. A normal neurologic examination reduces the odds

\section{Box 1: Choosing Wisely recommendations} on imaging for headache

Don't do imaging for uncomplicated headache unless red flags are present.

- Red flags include recent onset, rapidly increasing frequency and severity of headache; headache causing the patient to wake from sleep; associated dizziness, lack of coordination, tingling or numbness, new neurologic deficit; and new onset of a headache in a patient with a history of cancer or immunodeficiency.

Source: Canadian Association of Radiologists. Five things physicians and patients should question. Choosing Wisely Canada. ${ }^{4}$
Competing interests: William Miller is vicepresident of the Canadian Association of Radiologists. No competing interests were declared by Santanu Chakraborty.

This article has been peer reviewed.

Correspondence to: William Miller, wmiller@toh.on.ca

CMAJ 2014. DOI:10.1503 /cmaj.141220 
of finding an abnormality by $30 \%$ (likelihood ratio 0.7$).^{3}$ In contrast, an abnormal neurologic examination increases the likelihood of finding important intracranial pathology (likelihood ratio 3.0). ${ }^{3}$

Guidelines and clinical decision rules are helpful in determining the need for imaging in headache. ${ }^{2,3,5,7}$ For example, inclusion of thunderclap onset (i.e., a red flag) and limited neck flexion (i.e., abnormal neurologic examination) resulted in $100 \%$ sensitivity when incorporated into the Ottawa Subarachnoid Hemorrhage Rule $;^{7}$ specificity was $15.3 \%$. In a patient with these findings, imaging would be indicated, with CT preferred to exclude acute hemorrhage ${ }^{2}$ and rapidly available at most sites (Box 2) ${ }^{2,4,5,8,9}$

Neuroimaging studies may be requested for fear of missing a diagnosis, or because of medicolegal concerns or patient expectation. A negative study can provide reassurance for both the patient and the referring physician, but this reassurance is difficult to quantify. ${ }^{10}$ As such, diagnostic scans for headache may be considered on an individual basis. A frank discussion with the patient stating the lack of impact of neuroimaging in the management of most headaches, the associated risk related to radiation exposure and the risks (both physical and psychological) related to false-positive results may be helpful.

When nonemergent imaging is indicated, magnetic resonance imaging is preferred over $\mathrm{CT}$, for higher sensitivity and to avoid radiation exposure. In general, CT is preferred in emergency situations and when acute hemorrhage is suspected $^{2}$ (Box 2).

Box 2: Recommendations for imaging for headache $e^{2,4,5,8,9}$

\begin{tabular}{|ll|}
\hline Red flags & Suggested tests \\
\hline $\begin{array}{l}\text { New onset of a headache in a } \\
\text { patient with a history of cancer or } \\
\text { immunodeficiency }\end{array}$ & $\begin{array}{l}\text { Enhanced MRI or contrast-enhanced } \\
\text { CT }^{5}\end{array}$ \\
\hline New neurologic deficit & \\
\hline $\begin{array}{l}\text { Rapidly increasing frequency and } \\
\text { severity of headache; thunderclap } \\
\text { onset; headache causing the patient } \\
\text { to wake from sleep }\end{array}$ & $\begin{array}{l}\text { Noncontrast } \mathrm{CT}^{2,5} \\
\text { angiogram in cases of thunderclap } \\
\text { onset to rule out aneurysm }\end{array}$ \\
\hline $\begin{array}{l}\text { First-degree relative with known } \\
\text { aneurysm or subarachnoid } \\
\text { hemorrhage }\end{array}$ & $\begin{array}{l}\text { Consider CT or MR angiogram to } \\
\text { rule out aneurysm }\end{array}$ \\
\hline $\begin{array}{l}\text { Associated dizziness, lack of } \\
\text { coordination, tingling or numbness }\end{array}$ & $\begin{array}{l}\text { Consider CT or MRI including } \\
\text { angiogram to rule out dissection or } \\
\text { vascular insufficiency }\end{array}$ \\
\hline $\begin{array}{l}\text { Headache associated with sexual } \\
\text { activity, orgasmic type with } \\
\text { thunderclap onset (nonacute) }\end{array}$ & $\begin{array}{l}\text { Consider CT or MRI including } \\
\text { angiogram to rule out aneurysm or } \\
\text { dissection }\end{array}$ \\
\hline Note: CT = computed tomography, MRI = magnetic resonance imaging. \\
\hline
\end{tabular}

\section{With the patient's family history, does she require screening for cerebral aneurysm?}

With a family history of one distant relative with cerebral aneurysm, the patient does not meet the criteria of screening recommendations.

The incidence of familial aneurysms among patients with subarachnoid hemorrhage is up to $20 \%{ }^{11}$ Screening of first-degree relatives is generally recommended in families that have two or more individuals with aneurysms. However, the latest guideline by the American Heart Association and American Stroke Association ${ }^{8}$ finds it reasonable to offer noninvasive screening to families with one first-degree relative with subarachnoid hemorrhage. The interval at which the screening should be repeated is controversial, but most costeffectiveness models suggest an interval of five to seven years. ${ }^{12}$ Technically, CT angiogram has a slightly better resolution than magnetic resonance angiogram. However, magnetic resonance angiogram does not require contrast and is radiationfree, making it the preferred investigation for screening for cerebral aneurysms. ${ }^{12}$

\section{Does this patient require screening for aneurysm, given that she had headache with sexual activity?}

The patient's history of headaches that are only occasionally associated with sexual intercourse makes it unlikely that these headaches are associated with aneurysm.

Headache associated with sexual activity is not common. However, one estimate suggests that $4 \%-11 \%$ of subarachnoid hemorrhages occur during sexual intercourse (about four per million people per year). ${ }^{9}$ Headache associated with sexual activity is more common in men (3:1) and is frequently bilateral. ${ }^{9}$ This type of headache mostly represents a benign primary disorder and is often associated with migraine $(25 \%)$, exertional headache $(29 \%)$ or tension-type headache $(45 \%) .{ }^{9}$ However, headache with sexual activity can occasionally be caused by important pathology. It is prudent to differentiate between dull, aching pain that occurs during preorgasm (found in $25 \%$ of headaches associated with sexual activity) and sudden explosive onset of headache that occurs during orgasm (75\%). The latter is more likely to be associated with subarachnoid hemorrhage or arterial dissection; brain and vascular imaging would be helpful in this situation. ${ }^{9}$

\section{Case revisited}

Because there is evidence of possible papilledema on examination, imaging to exclude idiopathic intracranial hypertension or tumour is reasonable. Magnetic resonance imaging, preferably 
with a magnetic resonance venogram, would be preferred over CT. Lumbar puncture with measurement of opening pressure may be diagnostic for idiopathic intracranial hypertension, the most likely diagnosis in this case. If, however, this patient did not have findings of papilledema, imaging would not be indicated.

\section{References}

1. You JJ, Purdy I, Rothwell DM, et al. Indications for and results of outpatient computed tomography and magnetic resonance imaging in Ontario. Can Assoc Radiol J 2008;59:135-43.

2. Douglas AC, Wippold FJ II, Broderick DF, et al. ACR Appropriateness Criteria Headache. J Am Coll Radiol 2014;11:657-67.

3. Frishberg BMRJ, Matchar DB, McCrory DC. Evidence-based guidelines in the primary care setting: neuroimaging in patients with nonacute headache. Minneapolis (MN): American Academy of Neurology; 2005. Available: http://tools.aan.com /professionals/practice/pdfs/gl0088.pdf (accessed 2014 Oct. 30).

4. Canadian Association of Radiologists. Five things physicians and patients should question. Choosing Wisely Canada; 2014 Available: www.choosingwiselycanada.org/recommendations /canadian-association-of-radiologists-2 (accessed 2014 Oct. 27).

5. 2012 CAR diagnostic imaging referral guidelines. Ottawa: Canadian Association of Radiologists; 2012. Available: www .carca/uploads/standards\%20guidelines/car-referralguidelines-a -en-20120927pdf (accessed 2014 Oct. 30)

6. Loder E, Weizenbaum E, Frishberg B, et al. Choosing wisely in headache medicine: the American Headache Society's list of five things physicians and patients should question. Headache 2013;53:1651-9.

7. Perry JJ, Stiell IG, Sivilotti ML, et al. Clinical decision rules to rule out subarachnoid hemorrhage for acute headache. JAMA 2013;310:1248-55.

8. Connolly ES Jr, Rabinstein AA, Carhuapoma JR, et al. Guidelines for the management of aneurysmal subarachnoid hemorrhage: a guideline for healthcare professionals from the American Heart Association/American Stroke Association. Stroke 2012:43:1711-37.

9. Frese A, Eikermann A, Frese K, et al. Headache associated with sexual activity: demography, clinical features, and comorbidity. Neurology 2003;61:796-800.

10. Howard L, Wessely S, Leese M, et al. Are investigations anxiolytic or anxiogenic? A randomised controlled trial of neuroimaging to provide reassurance in chronic daily headache. J Neurol Neurosurg Psychiatry 2005;76:1558-64.

11. Schievink WI, Schaid DJ, Michels VV, et al. Familial aneurysmal subarachnoid hemorrhage: a community-based study. J Neurosurg 1995;83:426-9.

12. Bor AS, Koffijberg H, Wermer MJ, et al. Optimal screening strategy for familial intracranial aneurysms: a cost-effectiveness analysis. Neurology 2010;74:1671-9.

Affiliation: Department of Medical Imaging, The Ottawa Hospital, Ottawa, Ont.

Contributors: Both authors contributed substantially to the conception of the article, drafted and revised the article, gave final approval of the version to be published and agree to act as guarantors of the work.

CMAJ is collaborating with Choosing Wisely Canada (www.choosingwiselycanada.org), with support from Health Canada, to publish a series of articles describing how to apply the Choosing Wisely Canada recommendations in clinical practice. 